University of Nebraska - Lincoln

DigitalCommons@University of Nebraska - Lincoln

April 1977

\title{
AN ANALYSIS OF THE DEPENDENCY STRUCTURE BETWEEN A GILT'S PREBREEDING AND REPRODUCTIVE TRAITS. I. PHENOTYPIC AND GENETIC CORRELATIONS
}

\author{
L. D. Young \\ Oklahoma Agricultural Experiment Station, Stillwater \\ R. K. Johnson \\ University of Nebraska-Lincoln, rjohnson5@unl.edu \\ I. T. Omtvedt \\ Oklahoma Agricultural Experiment Station, Stillwater 74074 and U.S. Department of Agriculture, El Reno, \\ OK, iomtvedt1@unl.edu
}

Follow this and additional works at: https://digitalcommons.unl.edu/animalscifacpub

Part of the Animal Sciences Commons

Young, L. D.; Johnson, R. K.; and Omtvedt, I. T., "AN ANALYSIS OF THE DEPENDENCY STRUCTURE BETWEEN A GILT'S PREBREEDING AND REPRODUCTIVE TRAITS. I. PHENOTYPIC AND GENETIC CORRELATIONS" (1977). Faculty Papers and Publications in Animal Science. 13.

https://digitalcommons.unl.edu/animalscifacpub/13

This Article is brought to you for free and open access by the Animal Science Department at DigitalCommons@University of Nebraska - Lincoln. It has been accepted for inclusion in Faculty Papers and Publications in Animal Science by an authorized administrator of DigitalCommons@University of Nebraska - Lincoln. 


\title{
AN ANALYSIS OF THE DEPENDENCY STRUCTURE BETWEEN A GILT'S PREBREEDING AND REPRODUCTIVE TRAITS. I. PHENOTYPIC AND GENETIC CORRELATIONS ${ }^{1}$
}

\author{
L. D. Young ${ }^{2}$, R. K. Johnson ${ }^{3}$ and I. T. Omtvedt ${ }^{4}$ \\ Oklaboma Agricultural Experiment Station, Stillwater 74074 and \\ U.S. Department of Agriculture, El Reno 73036
}

\section{SUMMARY}

This study involved the records of 339 purebred Duroc, Hampshire and Yorkshire gilts and 192 two-breed cross gilts resulting from matings among the three breeds. The primary purpose of this paper was to investigate the relationship of prebreeding traits, including the growth of the gilt and her littermates, with subsequent measures of reproduction. Heritabilities were estimated for several traits and in general the estimates were somewhat higher than most estimates in the literature. Genetically, all measures of growth were favorably and moderately to highly correlated to ovulation rate, with the relationship being stronger for traits measured late in growth as compared to traits measured early in growth. The only traits that had large genetic correlations with number of corpora lutea per embryo were birth weight $\left(r_{g}=-.90\right)$ and weaning weight $\left(r_{g}=.91\right)$.

None of the phenotypic correlations between prebreeding traits and reproductive traits were large and only eight of the 68 correlations were significant. Gilts which grew faster, were younger at $100 \mathrm{~kg}$, were heavier at breeding and had more days from $100 \mathrm{~kg}$ to breeding also had higher ovulation rates. Gilts which were heavier and older at breeding and had more days from $100 \mathrm{~kg}$ to breeding also had more embryos.

\footnotetext{
${ }^{1}$ Journal Article 3153 of the Agricultural Experiment Station, Oklahoma State University, Stillwater. Research conducted by the Department of Animal Science and Industry (Project 1444) in cooperation with the U.S.D.A., Agricultural Research Service, Southern Region.

${ }^{2}$ Present address: U. S. Meat Animal Research Center, Clay Center, NE 68933.

${ }^{3}$ Department of Animal Sciences and Industry, Oklahoma State University, Stillwater 74074.

${ }^{4}$ Department of Animal Science, University of Nebraska, Lincoln 68583.
}

A stepwise regression procedure was used to find the "best" model to predict ovulation rate (CL), number of embryos (EMB), embryo per corpora lutea (E/CL) and corpora lutea per embryo (CL/E). The "best" model accounted for only $15 \%, 18 \%, 9 \%$ and $6 \%$ of the variation in CL, EMB, E/CL and CL/E, respectively.

(Key Words: Growth, Reproduction, Phenotypic Correlations, Genetic Correlations.)

\section{INTRODUCTION}

Increasing litter size offers a tremendous opportunity to increase the overall efficiency of swine production. Basically the number of pigs born alive is determined by two parameters: number of ova shed per estrus (ovulation rate) and the proportion of eggs shed which are represented by live pigs at birth (embryo survival rate).

Bradford (1969) reported that ovulation rate and embryo survival rate in mice were under genetic control and were at least partially independent. Direct response to selection occurred in lines selected for ovulation rate and embryo survival rate; however, only the latter line showed an increase in litter size. A line successfully selected for increased litter size showed an increase in ovulation rate but no change in embryo survival rate. These results indicate that increased litter size can result from increases in either ovulation rate or embryo survival rate.

However, it is difficult and impractical for a commercial producer to determine ovulation rates and embryo survival rates on all females. If some traits measured before breeding can be found which are highly correlated, both genetically and phenotypically, with ovulation rate or embryo survival rate, then selection for increased litter size may be more efficient. 
This study was initiated to evaluate the phenotypic and genetic relationships existing between a gilt's prebreeding performance and her reproductive performance measured 30 days after breeding.

\section{MATERIALS AND METHODS}

This study includes the data from 339 purebred Duroc, Hampshire and Yorkshire gilts and 192 two-breed cross gilts resulting from matings among the three breeds. The gilts came from phase I and II of the Oklahoma swine crossbreeding project and represent eight breeding seasons from fall 1970 to spring 1974. The design of the above project was given in detail by Johnson et al. (1973) and Johnson and Omtvedt (1973). Distribution of the gilts by breed group and season is presented in table 1 .

Gilts were born at either the Experimental Swine Farm at Stillwater or the Fort Reno Livestock Research Station and different management systems were employed at the two stations.

Gilts at Stillwater were born in crates. Three to 5 days after birth, approximately one third of the litters and their dams were placed in individual pens with solid concrete floors open to the south. The remaining litters and their dams were kept in pasture lots until weaning with two litters per lot. All litters were weaned at 42 days, were placed on the test floor at 8 weeks of age and growth was measured from 9 weeks of age to 100 kilograms. When gilts reached $100 \mathrm{~kg}$, they were taken off the test floor and transferred to Fort Reno during seasons when only purebred gilts were mated at Fort Reno.

The gilts born at Fort Reno were also born in crates. At about 3 days of age they were moved with their dam to a concrete nursery pen with 1 litter per pen. The pigs were given access to creep feed at 21 days and the sow was removed at 42 days. The pigs were moved to a confinement feeding facility at 8 weeks of age and growth was measured from 9 weeks of age to 100 kilograms.

In the fall of 1970 and 1972 all purebred gilts were born at Stillwater. In the remaining seasons, the majority of the purebred gilts were born at Stillwater. All crossbred gilts were born at Fort Reno. In the seasons in which purebred and two-breed cross gilts were mated at Fort Reno, some of the purebred gilts had been born at Stillwater. These gilts had been transferred to Fort Reno at weaning and were placed on the growth test at Fort Reno with the Fort Reno born gilts. Thus, preweaning data on these gilts was obtained at Stillwater and postweaning data was obtained at Fort Reno. No attempt was made to correct for these various methods of handling. These different management systems probably created the most bias in weaning weights and litter size at weaning. Within a season-breed subclass all postweaning data was collected in contemporary surroundings. Sires used in this study were selected mainly on growth rate and back-fat. A total of 117 different sires were used. Twenty-seven of these sires were used in two or more seasons. This resulted in 168 sires within season-breed subclass.

After reaching $110 \mathrm{~kg}$, all gilts were maintained at Fort Reno in drylot. The gilts were limit fed and were hand mated so as to produce a litter at approximately 1 year of age. However, the gilts used in this study were slaughtered approximately 30 days after breeding

TABLE 1. DISTRIBUTION OF GILTS BY BREED GROUP AND BREEDING SEASON

\begin{tabular}{|c|c|c|c|c|c|c|c|c|c|c|}
\hline \multirow[b]{2}{*}{ Season } & \multicolumn{9}{|c|}{ Breed group ${ }^{\mathrm{a}}$} & \multirow[b]{2}{*}{ Total } \\
\hline & DD & DH & DY & HD & $\mathbf{H H}$ & HY & YD & YH & YY & \\
\hline 70 Fall & 14 & & & & 16 & & & & 15 & 45 \\
\hline 71 Spring & 29 & & & & 24 & & & & 8 & 61 \\
\hline 71 Fall & 14 & 8 & 8 & 5 & 10 & 3 & 10 & 9 & 11 & 78 \\
\hline 72 Spring & 16 & 13 & 10 & 7 & 21 & 8 & 12 & 14 & 13 & 114 \\
\hline 72 Fall & 21 & & & & 18 & & & & 10 & 49 \\
\hline 73 Spring & 11 & & & & 20 & & & & 11 & 42 \\
\hline 73 Fall & 7 & 8 & 9 & 8 & 12 & 7 & 7 & 8 & 7 & 73 \\
\hline 74 Spring & 14 & 7 & 6 & 5 & 9 & 6 & 7 & 7 & 8 & 69 \\
\hline Total & 126 & 36 & 33 & 25 & 130 & 24 & 36 & 38 & 83 & 531 \\
\hline
\end{tabular}

${ }^{a}$ First letter indicates breed of sire of gilt, second letter indicates breed of dam of gilt. 
to provide information on ovulation rate, number of embryos and embryo survival rate. At slaughter, gilts were probably of various physiological ages because breeding was done on a calendar date, not at a particular estrus cycle.

The traits evaluated before breeding were: the number of live pigs in the litter the gilt came from at birth (NB) and weaning (NW); her birth weight (BW), weaning weight (WW), average daily gain (ADG) and age at $100 \mathrm{~kg}$ (AGE); the average of the litter she was born in for birth weight (LBW), weaning weight (LWW), average daily gain (LADG) and age at $100 \mathrm{~kg}$ (LAGE); the deviation of the gilt's record from the litter average for birth weight (BWD), weaning weight (WWD), average daily gain (ADGD) and age at $100 \mathrm{~kg}$ (AGED); as well as breeding age (BRAGE), breeding weight (BRWT) and days from $100 \mathrm{~kg}$ to breeding (DAYS). DAYS was included to determine if this period of physiological maturation was useful in predicting fertility. Gilts with high values for DAYS may have an opportunity to go through more cycles before breeding. The reproductive traits evaluated were: number of corpora lutea (CL), number of live embryos (EMB), the ratio of number of embryos to number of corpora lutea (E/CL) and its reciprocal (CL/E). All traits were considered to be traits of the gilt. A previous analysis of a portion of these data (Young et al., 1974) indicated that the gilt's individual record was not highly correlated with her reproductive ability. In view of these results and the rather large maternal effect on several of the traits measured, the litter averages and the gilt's deviation from the litter average were each studied to see if they were more reliable indicators of reproductive ability than was the gilt's individual performance.

These data were analyzed assuming a nested or hierarchical design in order to estimate components of variance for genetic correlations and heritabilities. However, in four seasons, purebred sires could have produced purebred gilts as well as two types of crossbred gilts. For example, a Duroc sire could have produced purebred Duroc, Duroc $\times$ Hampshire or Duroc $x$ Yorkshire gilts. Sires within a breed were not represented by equal numbers of the various types of gilts. In an attempt to remove this bias, the following model was fit for all traits using the four seasons of data where sires produced both purebred and crossbred gilts:

$$
\begin{aligned}
& Y_{i j k m}=\mu+A_{i}+S_{j}+D_{k(j)}+(A S)_{i j}+ \\
& \quad(A D)_{i k(j)}+e_{i j k m}
\end{aligned}
$$

where,

$\mathrm{Y}_{\mathrm{ijkm} \mathbf{m}}=$ observed value of the trait for the ijkm ${ }^{\text {th }}$ observation

$\mu=$ overall mean

$A_{i}=$ effect of the $i^{\text {th }}$ season

$S_{j}=$ effect of the $j^{\text {th }}$ sire breed

$D_{k(j)}=$ effect of $k^{\text {th }}$ breed of dam within $j^{\text {th }}$ sire breed

$(A S)_{i j}$ and $(A D)_{i k(j)}$ are interaction terms

$\mathrm{e}_{\mathrm{ijkm}}=$ random element.

All effects were considered fixed except $e_{\mathbf{i j k m}}$. The record of each crossbred gilt was adjusted to a purebred gilt equivalent based on the breed of sire. For example, Duroc $x$ Hampshire and Duroc $\times$ Yorkshire gilts were adjusted to purebred Duroc. Adjustments were made by using differences among appropriate least squares means for the trait when either $D_{k(j)}$ or $(\mathrm{AD})_{\mathrm{ik}(\mathrm{j})}$ was a significant source of variation at the .10 level. There were three different $(\mathrm{AD})_{\mathrm{ik}(\mathrm{j})}$ for each trait and there were 19 traits. Twenty-seven of the possible 57 interactions of season with breed of dam within breed of sire were significant at the .10 level. This adjustment attempts to make the expected value of the crossbred equal to its purebred half-sib as well as attempting to remove breed of dam of gilt and heterosis effects. Using the adjusted data set, estimates of heritability $\left(h^{2}\right)$ and genetic $\left(r_{g}\right)$ and phenotypic $\left(r_{p}\right)$ correlations among the traits were obtained from a full-sib analysis. Estimates of heritability and genetic correlations are half-sib estimates. The expected mean squares from the hierarchal analysis are presented in table 2 .

Heritabilities and genetic correlations involving the deviation traits (BWD, WWD, ADGD and AGED) were not calculated. The expected

TABLE 2. EXPECTED MEAN SQUARES

\begin{tabular}{lrl}
\hline Source & df & EMS \\
\hline Season breed comb. & 23 & \\
Sire/w S-B.C. & 144 & $\sigma_{\omega}^{2}+1.45 \sigma_{d}^{2}+2.96 \sigma_{\mathrm{s}}^{2}$ \\
Dams/w sires & 211 & $\sigma_{\omega}^{2}+1.33 \sigma_{d}^{2}$ \\
Progeny/w dam & 152 & $\sigma_{\omega}^{2}$ \\
\hline
\end{tabular}


value of each sire mean for each of these traits is zero. Any deviations other than zero are due to sampling. Therefore, the sire components of variance and covariance and the heritabilities and genetic correlations involving these traits should be zero. Phenotypic correlations were calculated and are meaningful since common environmental effects could cause phenotypic relationships between the deviation traits and reproductive traits.

A stepwise regression analysis was conducted on each reproductive trait with all traits measured before breeding being included as potential independent variables. The effects of season and breed of gilt were included as dummy variables in all models. A maximum $R^{2}$ improvement technique was used (Barr and Goodnight, 1972). Only those models where the partial $F$ statistic was significant for all effects at the .10 level are reported.

\section{RESULTS AND DISCUSSION}

Heritabilities. Means and standard deviations and heritability estimates and their standard errors are presented in table 3. Standard errors of the heritability estimates were estimated according to procedures presented by Swiger $e t$ al. (1964).

Many of the heritability estimates, especially for NW, are higher than those generally reported in the literature. This may possibly

TABLE 3. MEANS, STANDARD DEVIATIONS, HERITABILITY ESTIMATES AND THEIR STANDARD ERRORS

\begin{tabular}{lccrl}
\hline Trait & Mean & \multicolumn{1}{l}{ SD } & $h^{2}$ & SE \\
\hline NB & 10.22 & 2.40 & -.05 & .18 \\
BW & 1.30 & .15 & .07 & .19 \\
LBW & 1.29 & .20 & .18 & .19 \\
NW & 7.82 & 1.90 & 1.18 & .21 \\
WW & 10.61 & 1.66 & .12 & .19 \\
LWW & 10.64 & 1.66 & .27 & .20 \\
ADG & .621 & .005 & 1.03 & .21 \\
LADG & .635 & .141 & -.71 & .14 \\
AGE & 187.1 & 9.8 & .70 & .21 \\
LAGE & 187.1 & 10.9 & .39 & .20 \\
BRAGE & 276.5 & 15.8 & .66 & .21 \\
BRWT & 120.3 & 9.3 & .74 & .21 \\
DAYS & 89.2 & 18.0 & .93 & .21 \\
CL & 13.48 & 2.33 & .21 & .20 \\
EMB & 10.50 & 2.71 & .39 & .17 \\
E/CL & .79 & .18 & -.22 & .18 \\
CL/E & 1.43 & .55 & .28 & .20 \\
\hline
\end{tabular}

${ }^{\mathrm{a}}$ Weights are in kilograms. result from the fact that preweaning data was obtained on gilts from two different stations, as previously described, and postweaning performance may be affected by preweaning management. Therefore, variation between sires was confounded with variation between stations since no attempt was made to adjust for station differences. This may have resulted in an overestimation of the sire component of variance. However, these estimates follow the general pattern normally found in that the $h^{2}$ for traits measured after weaning are larger than those measured while the pigs were under the influence of the maternal ability of the dam. All traits were considered traits of the gilt so that genetic correlations could be calculated using the paternal half-sib method. For the same reason observations of $\mathrm{NB}, \mathrm{NW}, \mathrm{LBW}$, LWW, LADG and LAGE were repeated for littermates; the resulting estimates of variance and covariance components for such traits are the same as if only one observation per litter had been used. The actual estimates of covariance components of the above traits with individual measures such as birth weight differ from those obtained by using one observation per litter because the method used in this study is the covariance between the mean birth weight of gilts present at breeding and the above traits. The estimates of heritability for all traits except $C L, E M B, E / C L$ and CL/E contain only the heritability of direct genetic effects. Heritability of the latter traits include the heritability of both direct genetic and maternal genetic effects since, in addition to direct genetic effects on these traits, the gilts maternal ability will affect her level of performance in these traits. The sire of the gilt affects the size of litter she was born in (NB) and weaned in (NW) only by direct genetic effects on liveability.

The sire component of variance was negative for NB, LADG, EMB and E/CL and resulted in negative heritability estimates. The heritability of .21 for CL was not significant and was half as large as the realized heritability of .40 reported by Zimmerman and Cunningham (1975). CL and EMB are direct measures of reproduction. The ratios of these numbers, $\mathrm{E} / \mathrm{CL}$ and $\mathrm{CL} / \mathrm{E}$, are both measures of embryo survival rate. High $\mathrm{E} / \mathrm{CL}$ and low $\mathrm{CL} / \mathrm{E}$ indicate high embryo survival rates. When E/CL was used as the measure of embryo survival, the sire component was negative. However, when $\mathrm{CL} / \mathrm{E}$ was used, the sire component was positive. Robison and Berruecos (1973), when evaluat- 
ing feed efficiency, noted differences in the sign of the sire component of variance for the ratios, feed/gain and gain/feed. The only negative components found were for gain/feed even though the corresponding estimates for feed/ gain, feed and gain were positive. These results indicate that the choice of which trait to use as the numerator can effect the results obtained.

Genetic Correlation. The genetic correlations among traits are reported above the diagonal in table 4. The main interest of this paper was to investigate the relationship of prebreeding traits with reproductive traits. Therefore, the correlations among prebreeding traits and among reproductive traits are presented but will not be discussed in this paper.

The sire component of variance was negative for EMB, E/CL, NB and LADG and prevented the estimation of genetic correlations when these traits were involved. BW, WW, LWW, ADG, BRWT and DAYS were positively and moderately to highly correlated with CL $\left(r_{g}=.41\right.$ to 1.96$)$, while AGE and LAGE were negatively and highly correlated with CL $\left(r_{g}=-1.21\right.$ and -.73 , respectively). These results indicate that some genes with above average effects for growth also have above average effects for ovulation rate. It also appears that later measures of growth are superior to early measures of growth in predicting genetic ability for ovulation rate.

A low value for $C L / E$ is desirable and reflects a high embryo survival rate. The correlations of LAGE, BRAGE and DAYS with $\mathrm{CL} / \mathrm{E}$ were small and had absolute values no greater than .10 . The correlations of NW, LWW, ADG, AGE and BRWT wtih CL/E were also low and had absolute values between .17 and .28. The traits which were highly correlated with CL/E were BW $\left(r_{g}=-.90\right.$ and $W W$ $\left(r_{g}=.91\right)$. This indicates that gilts which are genetically superior for birth weight are also genetically superior for embryo survival rate. In general, gilts which are genetically superior for weaning weight and postweaning growth are genetically inferior for embryo survival rate.

Squiers et al. (1952) estimated the correlations of age at breeding and weight at breeding with embryo mortality to be -.11 and -.05 , respectively. Rathnasabapathy et al. (1956) reported correlations of .32 and .35 for embryo mortality with age at breeding and gain from $90.7 \mathrm{~kg}$ to the 55 th day of gestation, respectively. Reddy et al. (1958) reported correlations of $.16, .11,-.21$ and .41 for embryo mortality with weight at 154 days, weight at breeding, rate of gain from 154 days to breeding and age at breeding, respectively. The above authors measured embryo mortality as the number of corpora lutea not represented by live embryos at slaughter.

In all cases, the correlations of the gilt's individual value for a trait with CL or CL/E was larger than the correlation of her litter average for the trait with $\mathrm{CL}$ or $\mathrm{CL} / \mathrm{E}$; indicating the gilt's own record is probably more valuable than her litter average.

Pbenotypic Correlations. The phenotypic correlations among all traits are presented below the diagonal in table 4 . Only the correlations of prebreeding traits with reproductive traits will be discussed.

All phenotypic correlations of prebreeding traits with reproductive traits were small and only eight out of 68 correlations, about $12 \%$, were significant $(\mathrm{P}<05)$. No traits measured before breeding were significantly correlated with either E/CL or CL/E. ADG, AGE, LAGE, BRWT and DAYS were significantly correlated with $\mathrm{CL}(\mathrm{r}=.21,-.16,-.15, .27$ and .18 , respectively) while BRAGE, BRWT and DAYS were significantly correlated with EMB $(r=.17$, .20 and .16 , respectively). This indicates that gilts which grow faster, are younger at $100 \mathrm{~kg}$, heavier at breeding and had more days from $100 \mathrm{~kg}$ to breeding also tend to ovulate more eggs. Gilts which had more days from $100 \mathrm{~kg}$ to breeding and were older and heavier at breeding tended to have more embryos.

Rathnasabapathy et al. (1956) found that weaning weight, 154-day weight and age at breeding were positively and significantly correlated with ovulation rate $(r=.33, .34$ and .32 , respectively) but showed no significant relationship to litter size. Squiers et al. (1952) found a correlation of .10 between growth rate and ovulation rate. Similar results have been found by Young and Omtvedt (1973). Reddy et al. (1958) reported that the correlation of ovulation rate with weight and age at breeding was .35 and .56 , respectively, and the correlation of litter size with age at breeding was .41 . Several workers (Stewart, 1945; Olbrycht, 1943; Korkman, 1947; Omtvedt et al., 1965) have found a positive correlation between age at breeding and litter size.

Regression Models. The regression models for CL, EMB, E/CL and CL/E are presented in table 5. The models reported are those for which the partial $F$ statistic was significant at 


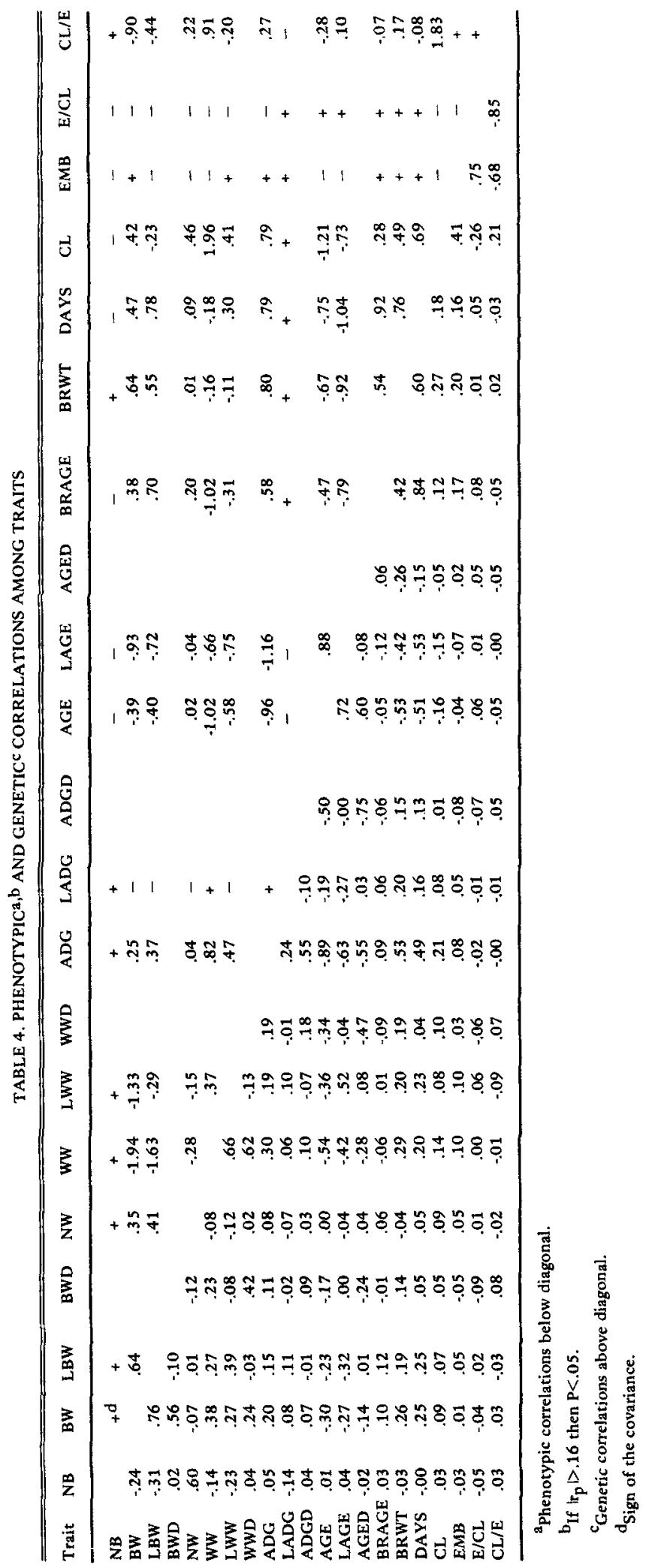


TABLE 5. MAXIMUM $R^{2}$ REGRESSION RESULTS WITH DEPENDENT VARIABLE CL, EMB, E/CL AND CL/E

\begin{tabular}{lll}
\hline \hline $\begin{array}{l}\text { Dependent } \\
\text { variable }\end{array}$ & Model & $\mathrm{R}^{2}$ \\
\hline $\mathrm{CL}$ & $\beta \mathrm{o}^{\mathrm{a}}$ & .068 \\
$\mathrm{CL}$ & $\beta \mathrm{o}+.0246 \mathrm{BRWT}$ & .140 \\
$\mathrm{CL}$ & $\beta \mathrm{o}+.0248 \mathrm{BRWT}+.0870 \mathrm{NW}$ & .146 \\
$\mathrm{EMB}$ & $\beta \mathrm{o}^{\mathrm{a}}$ & .127 \\
$\mathrm{EMB}$ & $\beta \mathrm{o}+.0210 \mathrm{BRWT}$ & .162 \\
$\mathrm{EMB}$ & $\beta \mathrm{o}+.0224 \mathrm{BRWT}-2.6926 \mathrm{ADGD}$ & .172 \\
$\mathrm{EMB}$ & $\beta \mathrm{o}+.0232 \mathrm{BRWT}-2.4672 \mathrm{ADGD}-.5613 \mathrm{BWD}$ & .177 \\
$\mathrm{E} / \mathrm{CL}$ & $\beta \mathrm{o}^{\mathrm{a}}$ & .075 \\
$\mathrm{E} / \mathrm{CL}$ & $\beta \mathrm{O}-.0542 \mathrm{BWD}$ & .085 \\
$\mathrm{E} / \mathrm{CL}$ & $\beta \mathrm{o}-.0533 \mathrm{BWD}+.0008 \mathrm{BRAGE}$ & .091 \\
$\mathrm{CL} / \mathrm{E}$ & $\beta \mathrm{o}^{\mathrm{a}}$ & .049 \\
$\mathrm{CL} / \mathrm{E}$ & $\beta \mathrm{O}+.1460 \mathrm{BWD}$ & .057 \\
$\mathrm{CL} / \mathrm{E}$ & $\beta \mathrm{o}+.1384 \mathrm{BWD}-.0136 \mathrm{LWW}$ & .063 \\
\hline
\end{tabular}

${ }^{\mathrm{a}}$ Mean after fitting season and breed of gilt.

the .10 level for every effect in the model.

None of the models were very successful in predicting the four measures of reproductive performance. The "best" single variable model was very similar for $\mathrm{CL}$ and EMB. The variable included in this model was BRWT and the regression coefficients were very similar for both traits. The next and last variable picked to predict CL was NW. When it was included, the "best" two variable model accounted for approximately $15 \%$ of the variation in ovulation rate. This indicates that gilts which are heavy at breeding and are selected from litters which are large at weaning should, on the average, have higher than average ovulation rates. The "best" model to predict EMB included BRWT, ADGD and BWD and accounted for about $18 \%$ of the variation in number of embry os. Because of the negative coefficients for ADGD and BWD, these results may indicate that gilts that are below litter average for birth weight and average daily gain but are taken to heavy weights before breeding should have more embryos than the average.

BWD was chosen to be in the "best" one-variable model to predict both E/CL and $\mathrm{CL} / \mathrm{E}$. The "best" two-variable model for E/CL includes BWD and BRAGE and accounted for approximately $9 \%$ of the variation in $\mathrm{E} / \mathrm{CL}$. While the "best" two-variable model for $\mathrm{CL} / \mathrm{E}$ accounted for only $6 \%$ of the variation and included BWD and LWW. Prediction of embryo survival rate (E/CL and $C L / E)$ was not as successful as the prediction of the components of embryo survival rate (CL and EMB). It is interesting to note that the first variable chosen to predict CL and EMB was a measure of growth taken late in life (BRWT) while the first variable chosen to predict embryo survival (E/CL or CL/E) was a measure of growth taken early in life (BWD). By fitting season and breed of gilt $(\beta \mathrm{o})$, one could account for $6.8,12.7$, 7.5 and $4.9 \%$ of the variation in CL, EMB, $\mathrm{E} / \mathrm{CL}$ and $\mathrm{CL} / \mathrm{E}$, respectively.

In general, these data indicate that gilts which are genetically superior for growth are genetically superior for ovulation rate but possibly genetically inferior for embryo survival rate. Gilts which grew faster, were heavier and older at breeding and had more days from 100 $\mathrm{kg}$ to breeding tended to have higher ovulation rates and more embryos. Very little of the variation in $\mathrm{CL}, \mathrm{EMB}, \mathrm{E} / \mathrm{CL}$ or $\mathrm{CL} / \mathrm{E}$ could be accounted for by regression on the traits measured before breeding.

\section{LITERATURE CITED}

Barr, A. J. and J. H. Goodnight. 1972. A User's Guide to the Statistical Analysis System. Student Supply Stores, N. Carolina State University, Raleigh.

Bradford, G. E. 1969. Genetic control of ovulation rate and embryo survival in mice. I. Response to selection. Genetics 61:905. 
Johnson, R. K. and I. T. Omtvedt. 1973. Evaluation of purebreds and two-breed crosses in swine: Reproductive performance. J. Anim. Sci. 37:1279.

Johnson, R, K., I. T. Omtvedt and L. E. Walters. 1973. Evaluation of purebreds and two-breed crosses in swine: Feedlot performance and carcass merit. J. Anim. Sci. 37:18.

Korkman, Nils. 1947. Causes of variation in the size and weight of litters from sows. Acta. Agr. Suencana 2(3): 253.

Olbrycht, T. M. 1943. The statistical basis of selection in animal husbandry. I. Studies on life performance of brood sows: an analysis of variance and covariance of progeny born and reared. J. Agr. Sci. 33: 28 .

Omtvedt, I. T., C. M. Stanislaw and J. A. Whatly, Jr. 1965. Relationship of gestation length, age and weight at breeding and gestation gain to sow productivity at farrowing. J. Anim. Sci. 24:531.

Rathnasabapathy, V., J. F. Lasley and D. T. Mayer. 1958. Genetic and environmental factors affecting litter size in swine. MO. Agr. Exp. Sta. Res. Bull. 615 .

Reddy, V. B., J. F. Lasley and D. T. Mayer. 1958. Genetic aspects of reproduction in swine. MO. Agr. Exp. Sta. Res. Bull. 666.

Robison, O. W. and J. M. Berruecos. 1973. Feed efficiency in swine. I. A comparison of measurement periods and methods of expressing feed efficiency. J. Anim. Sci. 37:643.

Squiers, C. D., G. E. Dickerson and D. T. Mayer. 1952. Influence of inbreeding, age and growth rate of sows on sexual maturity, rate of ovulation, fertilization and embryo survival. MO. Agr. Exp. Sta. Res. Bull. 494.

Stewart, H. A. 1945. An appraisal of factors affecting prolificacy in swine. J. Anim. Sci. 4:250.

Swiger, L. A., W. R. Harvey, D. O. Everson and K. E. Gregory. 1964. The variance of intraclass correlation involving groups with one observation. Biometrics. 20: 818 .

Young, L. D. and 1. T. Omtvedt. 1973. Influence of the litter in which a gilt is raised and her own performance on her subsequent reproductive performance. Okla. Agr. Exp. Sta. Res. Rep. MP-90:177.

Young, L. D., I. T. Omtvedt and R. K. Johnson. 1974. Relationships of various measures of performance with ovulation rate and number of embryos 30 days after breeding in gilts. J. Anim. Sci. 39:480.

Zimmerman, Dwane R. and P. J. Cunningham. 1975. Selection for ovulation rate in swine: Population, procedures and ovulation response. J. Anim. Sci. 40:61. 